\title{
Correction to: An Investigation of the Effects of Brief Mindfulness Training on Self-Reported Interoceptive Awareness, the Ability to Decenter, and Their Role in the Reduction of Depressive Symptoms
}

\author{
Maria Fissler $^{1,2} \cdot$ Emilia Winnebeck $^{1,2} \cdot$ Titus Schroeter $^{1} \cdot$ Marie Gummersbach $^{1} \cdot$ Julia M. Huntenburg ${ }^{1}$. \\ Matti Gaertner ${ }^{1} \cdot$ Thorsten Barnhofer $^{1,3}$ (D)
}

Published online: 13 February 2019

(C) Springer Science+Business Media, LLC, part of Springer Nature 2019

Correction to: Mindfulness (2016) 7:1170-1181

https://doi.org/10.1007/s12671-016-0559-z

Maria Fissler and Emilia Winnebeck also are affiliated with the Department of Psychiatry and Psychotherapy, CharitéUniversitätsmedizin Berlin, Campus Benjamin Franklin, Hindenburgdamm 30, 12203 Berlin, Germany

Publisher's Note Springer Nature remains neutral with regard to jurisdictional claims in published maps and institutional affiliations.

The online version of the original article can be found at https://doi.org/ 10.1007/s12671-016-0559-z

Thorsten Barnhofer

t.barnhofer@exeter.ac.uk

1 Dahlem Center for Neuroimaging of Emotions, Freie Universität

Berlin, Berlin, Germany

2 Department of Psychiatry and Psychotherapy,

Charité-Universitätsmedizin Berlin, Campus Benjamin Franklin, Hindenburgdamm 30, 12203 Berlin, Germany

3 Mood Disorders Centre, University of Exeter, Sir Henry Wellcome Building for Mood Disorders Research, Perry Road, Exeter EX4 4QG, UK 